\title{
Diş Hekimliği Öğrencilerinde Sınav Dönemi Algılanan Stres ile Bruksizm İlişkisinin Değerlendirilmesi
}

\author{
The Relationship Between Perceived Stress and Bruxism at Examination \\ Period in Dentistry Students
}

\author{
Mehmet Esad GÜVEN ${ }^{* 1}$ (D) \\ meguven@erbakan.edu.tr
}

\author{
Ali ALTINDAĞ $\breve{G}^{2}$ \\ aaltindag@erbakan.edu.tr
}

\author{
Şakir GICA ${ }^{3}$ iD \\ sakirgica@hotmail.com
}

\begin{abstract}
öZ
Amaç: Bu çalışmanın amacı diş hekimliği fakültesi öğrencileri arasında sınav döneminde algılanan stres düzeyi ile bruksizm, temporomandibular rahatsızlıkların (TMR) ilișkisini değerlendirmektir.

Gereç ve Yöntemler: Diş Hekimliği Fakültesi 4. Ve 5. Sınıf öğrencilerinden gönüllü olan 102 kişiye sınav haftasından 4 hafta önce ve sınav haftasında sosyodemografik ve alışkanlıkları içeren sorular ile Fonseca Anamnestik Indeksi (FAI) ve Algılanan Stres Ölçeği (ASÖ) anketi yöneltilmiștir. Katılımcıların kendi beyanları esas alınmıștır. Paired Student T test ve Pearson Korelasyon testi kullaanılmıștır. Anlamlılık düzeyi p<0,05 alınmıștır

Bulgular: Sınav haftası daha yüksek FAI skorları izlenmiştir. Kadınlar erkeklerden anlamlı derecede daha yüksek FAI ve ASÖ skorları göstermiştir. ASÖ skorları açısından sınav öncesi ve sınav haftası arasında anlamlı fark yoktur. FAI ve ASÖ skorları değişimleri arasında yüksek pozitif korelasyon vardır. Sınıf düzeyi ve aile yanında yaşamak FAI ve ASÖ skorlarını etkilememiştir

Sonuç: Sınav FAI ve ASÖ skorlarını artırmaktadır. Bruksizm ve algılanan stres arasında güçlü bir ilişki gözlemlenmiştir. Stres bir bruksizm nedeni olarak gösterilebilir.
\end{abstract}

Anahtar Kelimeler: Bruksizm, Algılanan stres ölçeği, Fonseca anamnestik indeksi

Geliş: 21.11.2021 Kabul: 26.12.2021 Yayın: 29.12.2021

\begin{abstract}
Aim: The aim of this study is to evaluate the relationship between perceived stress and bruxism, temporomandibular disorder among dentistry students.

Material and Methods: 102 of the 4th and 5th grade students of the university were asked questions about sociodemographic and habits, as well as Fonseca Anamnestic Index (FAI) and Perceived Stress Scale (PSS) questionnaire 4 weeks before and during the exam week. Based on the participants' self-reports. Paired Student T test and Pearson Correlation test were used.. Significance level was taken as $\mathrm{p}<0.05$

Results: Higher FAI scores were observed during the exam week. Female students showed significantly higher FAI and PSS scores than male's. There is no significant difference between pre-exam and exam week in terms of PSS scores. There is a high positive correlation between the changes in FAI and PSS scores. Class level and living with a family did not affect FAI and PSS scores.

Conclusion: The exam raises FAI and PSS scores. A strong relationship has been determined between bruxism and perceived stress. Stress can be shown as a cause of bruxism.
\end{abstract}

Keywords: Bruxism, Perceived stress scale, Fonseca anamnestic index

Received: 21.11.2021 Accepted: 26.12.2021 Published: 29.12 .2021

Atıf / Citation: Güven ME, Altındağ A, Gıca Ş. Diş hekimliği öğrencilerinde sınav dönemi algılanan stres ile bruksizm ilişkisinin değerlendirilmesi. NEU Dent J. 2021;3:122-7.

* Sorumlu Yazar / Corresponding Author

1. Necmettin Erbakan Üniversitesi, Diş Hekimliği Fakültesi, Protetik Diş Tedavisi AD, Konya, Türkiye

2. Necmettin Erbakan Üniversitesi, Diş Hekimliği Fakültesi, Ağız Diş ve Çene Radyolojisi AD, Konya,

Türkiye

3. Necmettin Erbakan Üniversitesi, Tıp Fakültesi, Pskiyatri AD, Konya, Türkiye
"This article is licensed under a Creative Commons AttributionNonCommercial 4.0 International License(CC BY-NC 4.0) 


\section{GíRiş}

Temporomandibular eklem (TME), dişler ve kaslar çiğneme sisteminin disfonksiyonundan etkilenen bölgeler olarak sıralanır. TME ve kas kaynaklı bozukluklar temporomandibular rahatsızlıklar (TMR) olarak adlandırılır. ${ }^{1}$ TMR'ler, stomatognatik sistemde ağrı, sınırlı temporomandibular eklem hareketleri, çene hareketleri sırasında eklemde ses ve/veya sert klik, baș ağrısı ve kulak çınlaması ile karakterizedir. ${ }^{2,3}$

Bruksizm ise en sik görülen temporomandibular rahatsızlıkardan biridir. Dental, sistemik ve psikolojik olarak çok faktörlü bir bozukluk olarak kabul edilmektedir ancak etiyolojisi tam olarak tanımlanmamıştır. ${ }^{4-8}$ Bazı çalışmalar ise genetik aktarımın bruksizm patogenezinde rol aldığını öne sürmektedir., ${ }^{9,10}$

Diğer yandan TMR teşhisi klinisyen için kolay olmayabilir. Etyolojik faktörlerin net olmaması ve rahatsızlığın multifaktöryel etkenli olması TMR hastalarının teşhisinde farklı değerlendirme yöntemleri kullanılmasını gündeme getirmektedir. ${ }^{11-13}$ Sağlıklı popülasyon içerisinde TMR araștırılmasında kullanılan indekslerden biri de "Fonseca Anamnestic Index (FAI)" dir. İndeksin maliyeti düşüktür, uygulaması kolaydır. Bu durum TMR hastalarında teşhisinde tercih nedenidir. FAI; 10 sorudan oluşan bir ankettir. Sorular TME, baş, sirt bölgelerinde ve çiğneme sırasında ağrının varlığına, parafonksiyonel alışkanlıklara, disfonksiyona, klik olup olmamasına, oklüzyon bozukluğuna, emosyonel stresin tespitine odaklanır. ${ }^{14}$

Stress de bruksizm patogenezinde önemli bir rol oynamakta ve izlenmesi ve değerlendirilmesi klinik olarak teşhiste yardımcıdır. Stres ise psikolojik, sosyal, mesleki ve okul ortamlarında evrensel olarak kullanılan ve iyi bilinen bir kelimedir: olumlu bir çağrışımdaki "yapıcı stres (eustress)" ve olumsuz bir anlamdaki "sıkıntı (distress)" sözcükleri, stresin olumlu ve olumsuz yönlerini tanımlar. Üniversite öğrencileri de, akademik sonuçlar ve kişisel, duygusal veya sağlık sonuçları açısından olumsuz sonuçlar nedeniyle ${ }^{15}$ aşırı miktarda stres yaşayabilirler. Üniversite öğrencilerindeki stres kaynakları ${ }^{16}$ akademik çalışmalar, kişisel durumlar, sosyal çevre, zaman ve ekonomik koşullar gibi durumlardır. Ayrıca stres, sadece üniversite yaşamı boyunca değil, öncesinde, lisans düzeyinden profesyonel düzeye geçiş sırasında ve sonrasında, iş hayatına geçiş sırasında da farklı zaman dilimlerinde ${ }^{17}$ yaşanabilmektedir.

Üniversite öğrencilerinde bruksizm ve stres arasındaki ilișki üzerine yapılan çalıșmalarda geçiș süreci, bağlllık ve zorlu üniversite ortamı ${ }^{18-20}$ gibi durumlar, öğrencilerin başa çıkması gereken durumlar haline gelebilir. Zorlandıklarında ise stresin olumsuz etkilerine açık hale gelirler.
Bu nedenle, bu çalışmada bir grup Diş Hekimliği Fakültesi öğrencisinde TMR ve sınav dönemiyle değişen algılanan stres seviyesi ile olan ilişkisi araştırılmıștır. Çalışmada șunlar değerlendirilmiștir.

(i)Üniversite öğrencilerinde bruksizm ve algllanan stresin yaygınlığı ve yoğunluğu;

(ii) Bruksizm ile algılanan stres arasındaki ilişki;

(iii) Bruksizm ve algılanan stres arasındaki korelasyonda cinsiyete ve/veya kişisel özelliklere bağlı farklılıkların varlığı.

\section{GEREÇ VE YÖNTEMLER}

Bu çalışma; algılanan stres düzeyi ve bruksizmi, sınav dönemi ile ilişkisini anket yoluyla değerlendirecek şekilde planlanmıştır ve uygulanmıştır. Çalışmanın popülasyonu Konya Necmettin Erbakan Üniversitesi Diş Hekimliği Fakültesi öğrencilerinden seçilmiştir. Genel olarak çalışmaya dahil edilme kriterleri şunlardır;

- 18-24 yaş aralığında olmak,

- Daha önce ortodontik tedavi görmemiş olmak,

- Herhangi bir maksillofasiyal travmaya maruz kalmamış olmak,

- Herhangi bir sebeple akut antibiyotik kullanmıyor olmak,

- $\quad$ Ağızda en az 20 diş olması,

- Hamilelik ve laktasyonda olmaması, herhangi düzenleyici bir ilaç tedavisi görmeyen kişiler olarak belirlenmiștir.

Çalışmaya dahil edilmeme kriterleri ise;

- Düzenli alkol kullanımı,

- İlaç ve/veya madde bağımlılığı,

- Psikiyatrik ilaç kullanımı,

- Miyorelaksan ilaç tedavisi görenler,

- Daha önce eklem disfonksiyonu nedeniyle invaziv ve/veya noninvaziv tedavi görenler ve

- Değerlendirme ölçeklerini ve anketleri tam olarak doldurmayan katılımcılar olarak belirlenmiștir.

Çalıșma Helsinki Bildirgesiınin yönergelerine göre yürütüldü. Çalışma protokolü Necmettin Erbakan Üniversitesi>nde Etik Komite tarafından onaylanmıștır (karar no: 2021/01-12) Çalışmaya XXXX Üniversitesi Diş Hekimliği Fakültesinde öğrenim gören klinik (4. (50 kişi) ve 5. Sınıf (52 kişi)) öğrencilerinden sınav 
zamanı içerisinde olanlar çalıșmaya dahil edilmiștir. Calıșmaya katılan gönüllülere sınav haftasından 4 hafta önce ve sınav haftası aynı sorular yöneltilmiștir. Sorular öğrencilere Google forms (GOOGLE INC Cal. ABD) platformu ile gönderilmiş ve öğrencilerden yanıt vermeleri istenmiştir. Gönüllülere 3 bölümden olușan bir anket yöneltilmiștir. Anket; araștırdığımız konuya etki edecek olan faktörlere ilișkin 14 soruluk bir sosyodemografik test, 10 sorudan oluşan fonseca anamnestik indeks (FAI) ve yine 10 sorudan oluşan bir Algılanan Stres Ölçeği'nden (ASÖ) oluşmaktadır. Fonseca anketin kullanılmasının nedeni, basit anlaşılır ve yeterliliğinin yüksek olmasıdır. Bu anket, parafanksiyonu, disfonksiyonu, eklem sesini maloklüzyonu, eklem bölgesinde, baş ve boyunda, çiğneme sırasında ağrı varlığını sorgular. Katılımcılar sorulara cevap olarak, Evet (10 puan), Bazen (5 puan) ve Hayır (0 puan) cevaplarından birini seçebilirler. Anket 10 sorudan oluşur. Anketin türk popülasyonunda geçerlilik ve güvenilirlik testleri Kaynak ve ark. tarafından yapılmıştır. ${ }^{21}$

"Ankette yer alan sorular aşağıdaki gibidir.

1. Ağzınızı açarken zorluk çekiyor musunuz?

2. Alt çenenizi sağa-sola kaydırırken zorluk çekiyor musunuz?

3. Çiğneme esnasında kaslarınızda yorgunluk/ağrı oluyor mu?

4. Sık sık baş ağrınız olur mu?

5. Ense ağrınız veya boyun tutulmanız oluyor mu?

6. Kulak veya temporomandibular eklem ağrınız oluyor mu?

7. Çiğneme veya ağız açma sırasında TME den herhangi bir klik sesi duyduğunuz oldu mu?

8. Diş sıkma veya gıcırdatma alışkanlığınız var mı?

9. Dişlerinizin düzgün kapanmadığını hissediyor musunuz?

10. Kendinizi gergin (asabi) biri olarak görür müsünüz?"

Anket sorularına verilen cevaplar Anamnestik İndeksine göre 4 kategoride sınıflandırılmıștır:

0-15 puan; TMR-yok

20-40 puan; hafif TMR

45-65 puan; orta TMR

70-100 puan; şiddetli TMR olarak tanımlanmıştır.

Yapılan bu anketin ardından kişinin bildirdiği stresi ölçen, yerleşik geçerliliği ve güvenilirliği olan Türkçe dilinde geçerlilik ve güvenilirlik çalışması $\mathrm{Erci}^{22}$ tarafından yapılan Algılanan Stres Ölçeği (Perception Stress Scale (PSS)) yapılmıștır. 5 puanlı Likert ölçeği kullanılarak sıralanan 10 soru içerir ve stresli deneyimleri ve önceki 4 hafta boyunca strese verilen tepkileri değerlendirir. Bu ölçekteki sorular șu șekildedir;

1. Geçen ay, beklenmedik bir şeylerin olması nedeniyle ne sıklıkta rahatsızlık duydunuz?

2. Geçen ay, hayatınızdaki önemli şeyleri kontrol edemediğinizi ne sıklıkta hissettiniz?

3. Geçen ay, kendinizi ne sıklıkta sinirli ve stresli hissettiniz?

4. Geçen ay, kişisel sorunlarınızı ele alma yeteneğinize ne sıklıkta güven duydunuz?

5. Geçen ay, her şeyin yolunda gittiğini ne sıklıkta hissettiniz?

6. Geçen ay, ne sıklıkta yapmanız gereken şeylerle başa çıkamadığınızı fark ettiniz?

7. Geçen ay, hayatınızdaki zorlukları ne sıklıkta kontrol edebildiniz?

8. Geçen ay, ne sıklıkta her şeyin üstesinden geldiğinizi hissettiniz?

9. Geçen ay, ne sıklıkta kontrolünüz dışında gelişen olaylar yüzünden öfkelendiniz?

10. Geçen ay, ne sıklıkta problemlerin üstesinden gelemeyeceğiniz kadar biriktiğini hissettiniz?

Olumsuz olayları veya tepkileri ilişkilendiren sorular ters bir şekilde puanlanır. Puanlar 0 ile 56 arasındadır ve daha yüksek puanlar daha yüksek algılanan stres seviyelerini gösterir.

\section{Ístatiksel Analiz}

Tanımlayıcı istatistiklerin yanı sıra, öğrencilerin sınav dönemi ve sonraki dönemdeki yanıtladıkları bruksizm ve algılanan stres ölçek skorlarının karşılaştırılmasında Paired Student T testi kullanılmıştır. Yine bruksizm semptomları, algılanan stres ve diğer demografik verilerin korelasyon analizlerinde Pearson Korelasyon testi kullanılmıștır. Sınav dönemindeki bruksizm semptomları ve algllanan stres düzeyleri değişim oranları tespit edildi (değișim oranı: ((ilk skor-ikinci skor)/ilk skor)*100). Bruksizm semptomlarındaki değişim üzerine etkili olan parametreler ise multivariate linear regresyon analizi ile olușturulan modelle incelenmiștir. İstatistiksel anlamlılık için, \% 5'lik bir toplam tip-1 hata seviyesi kullanıldı. Veriler SPSS (V 24, IBM Inc, CAL, ABD) ile analiz edildi. 


\section{BULGULAR}

Çalışmamıza, \%72,5'i kadın (n=74) ve \%27,5'i erkek (n=28) 102 gönüllü öğrenci katılmıștır. Buna göre gönüllülerin demografik verileri ve $p$ değerleri Tablo 1 de izlenmektedir.

Bruksizm geçmişi için "hiçbir zaman” ifadesi dışındakiler olumlu kabul edilmiş ve bruksizm prevelansına dahil edilmiştir. Buna göre katılımcıların \%57 si hayatlarında bir dönem brukszim veya TMR semptomları göstermiştir.

Fonseca anamestik indeksine göre; sinav haftası ve sınav öncesi değerler Tablo 2'de izlenmektedir. Buna göre; sınav haftası elde edilen değerler, sınav öncesi elde edilen değerlerden anlamlı derecede yüksektir $(p=0,004)$. Kadınlar, erkeklerden daha yüksek skorlar göstermiştir $(\mathrm{p}=0,000)$.
Ancak sınav öncesi ve sınav haftası algılanan stres düzeyi değerleri karșlaștırıldığında anlamlı bir farklılık izlenmemiştir $(p>0,05)$. Algılanan stres düzeyi değișimi cinsiyete göre anlamlı bir farklılık göstermiştir. $(p<0,05)$. Algılanan stres düzeyi değerleri Tablo 3'de yer almaktadır.

Öğrencilerin sınıf düzeyleri (4. veya 5. ) algılanan stres değeri ve fonseca anamnestik indeks skorları açısından değerlendirildiğinde anlamlı bir fark bulunamamıştır ( $p>0,05)$.

Öğrencilerin aile yanında/uzakta yaşama durumları ile, algılanan stres düzeyi ve fonseca skorları arasında anlamlı bir farklılık yoktur $(p>0,05)$ ve herhangi bir yönde korelasyon tespit edilmemiștir.

Fonseca skorları değișim ile algılanan stres ölçeği değerleri değișimi arasında yüksek anlamlı pozitif yönde bir korelasyon vardır (Pearson korelasyon değeri $0,306, p=0,002$ ).

Tablo 1: Katılımcların cinsiyete göre aile yanında yaşama, sigara kullanan ve alkol kullanan gruplarına göre dağıllımı ve p değerleri ( $\mathrm{p}<0,05$ düzeyinde test edilmiștir)

\begin{tabular}{|c|c|c|c|c|}
\hline Parametre & $\begin{array}{c}\text { Tüm Katılımcılar } \\
(\%)\end{array}$ & $\begin{array}{c}\text { Erkek } \\
(\%)\end{array}$ & $\begin{array}{c}\text { Kadın } \\
(\%)\end{array}$ & $\mathbf{p}$ \\
\hline Ailesi ile yaşayan & 38,2 & 35,7 & 40,2 & 0,124 \\
\hline Sigara kullanan & 13,7 & 15,9 & 8,1 & 0.023 \\
\hline Alkol kullanan & 2,8 & 4,5 & 0 & 0.001 \\
\hline
\end{tabular}

Tablo 2: Fonseca Anamnestik İndeks skorlarına göre TMR dağılımı ve yüzdeleri

\begin{tabular}{|c|c|c|c|c|c|c|c|}
\hline \multirow{2}{*}{\multicolumn{2}{|c|}{ TMR }} & \multicolumn{4}{|c|}{ Cinsiyet } & \multirow{2}{*}{\multicolumn{2}{|c|}{ Toplam }} \\
\hline & & \multicolumn{2}{|c|}{ Kadın } & \multicolumn{2}{|c|}{ Erkek } & & \\
\hline \multirow{4}{*}{$\begin{array}{c}\text { Sinav } \\
\text { Öncesi }\end{array}$} & YOK & 25 & $34 \%$ & 18 & $64 \%$ & 43 & $42 \%$ \\
\hline & HAFIF TMR & 27 & $36 \%$ & 10 & $36 \%$ & 37 & $36 \%$ \\
\hline & ORTA TMR & 20 & $27 \%$ & 0 & $0 \%$ & 20 & $20 \%$ \\
\hline & ŞİDDETLİ TMR & 2 & $3 \%$ & 0 & $0 \%$ & 2 & $2 \%$ \\
\hline \multirow{4}{*}{$\begin{array}{l}\text { Sinav } \\
\text { Haftası }\end{array}$} & YOK & 21 & $28 \%$ & 16 & $57 \%$ & 37 & $36 \%$ \\
\hline & HAFIF TMR & 31 & $42 \%$ & 10 & $36 \%$ & 41 & $40 \%$ \\
\hline & ORTA TMR & 20 & $27 \%$ & 2 & $7 \%$ & 22 & $22 \%$ \\
\hline & ŞiDDETLİ TMR & 2 & $3 \%$ & 0 & $0 \%$ & 2 & $2 \%$ \\
\hline
\end{tabular}

Tablo 3: Sınav öncesi ve sınav haftası Algılanan Stres Ölçeği (ASÖ) skorlarının cinsiyetlere göre dağılımı

\begin{tabular}{|c|c|c|}
\hline & Kadın & Erkek \\
\hline ASÖ Sınav Öncesi & 32,77 & 27,82 \\
\hline ASÖ Sınav haftası & 32,91 & 28,61 \\
\hline
\end{tabular}




\section{TARTIŞMA}

$\mathrm{Bu}$ çalışma üniversite öğrencileri arasında sınav dönemi ve sinav öncesi dönemde algılanan stres ile bruksizmin ilișkisini incelemiștir.

Buna göre bu çalışmada; katılımcıların \%57 si bruksist veya hayatlarının bir döneminde bruksizm geçmişi olduğu gözlemlenmiştir. Literatür incelendiğinde bruksizm prevelansı \%40'dan \%85'lere kadar çok farklı değerler sergilemektedir. ${ }^{16,23}$ Quadri ve ark. diș hekimliği fakültesi öğrencilerinde \%83'e kadar çıkabildiğini savunmuştur. ${ }^{23}$

$\mathrm{Bu}$ çalışmada üniversite öğrencilerinin bruksizm ve algılanan stres değerleri arasında pozitif yönde bir korelasyon mevcuttur ve yüksek oranda FAI-TMR skorları izlenmiştir. Stres ve bruksizm arasındaki ilişki; mesleki stres üzerinden incelenmiş, ve aralarında pozitif yönde bir ilșiki olduğu daha önce yapılan bir çalışmada bildirilmiştir. ${ }^{24}$ Stresin daha spesifik olarak, üniversite öğrencileri üzerindeki etkisini inceleyen bir diğer çalışmada, ağız ve çenede nöromüsküler değişiklikleri indükleyebilir ve temporo-mandibular bozuklukların genel prevalansını artırabilir olduğu sonucuna varılmıștır. ${ }^{25}$ Cavallo ve ark. ${ }^{26}$ da İtalyan öğrenciler üzerinde yaptıkları çalışmada ö ğrencilik stresinin hem gece hem de gündüz bruksizmi üzerinde etkisi olduğunu göstermişlerdir.

Diğer belirli bir üniversite/okul popülasyonunda yapılan çalışmalarda da bruksizm ve stres arasında güçlü bir ilişki olduğu bulunmuştur. ${ }^{27,28}$ Ayrıca son yayınlarda öğrencilerin kendi beyan ettiği gece bruksizmi oranlarının normal popülasyondan daha yüksek olduğu görülmüştür. ${ }^{23}$

Bu çalışmada kadınlar; daha yüksek TMR ve ASÖ skorları göstermiştir. Üniversite öğrencileri için streste cinsiyet farkının varlığı da mevcut literatürle tutarlıdır: çalışmaların çoğu, stresin kadınlar için daha yüksek olduğunu bildirmiştir. ${ }^{16,25,29}$ Diğer yandan çalışmada, kendi ailesi yanında yaşayan bireyler ile uzakta yaşayanlar arasında FAI ve ASÖ skorlarına göre fark çıkmamış ve aile yanında/uzakta yaşamak ile stres skorları arasinda herhangi bir korelasyon bulunmamıştır. Ancak Cavallo ve ark. ${ }^{26}$ çalışmalarında, ailesi ile yaşayan kadın katılımcılar için daha yüksek stres skorları gözlemlemişlerdir. Bu durumun daha yüksek psikolojik baskı ve beklentiler ile ilişkilendirilebilir olduğunu savunmaktadır. Ayrıca TMR'ın kadınlarda daha fazla görülmesinin bir nedeni de; östrojen salınımı olarak gösterilmektedir. Doğurgan kadınlarda TMR prevelansı, menapoz ve ergenlik öncesi döneme göre daha yüksek olduğunu gösteren çalışmalar mevcuttur. ${ }^{30,31}$

Çalışmamızda katılımcılarda sınav haftası daha yüksek TMR skorları izlenmiștir. Sınav, kendi başına bireylerin kaygı ve stresini artıran bir durumdur. Türken ve ark. ${ }^{32}$ Türk popülasyonu üzerinde diş hekimliği fakültesi öğrencileri üzerinde yaptıkları çalışmalarında; klinik sınıfı öğrencilerinde daha yüksek FAI skorları izlemişlerdir. Neden olarak ise; klinik öğrencilerinin staj eğitimleri ve gelecek kaygısı gibi dış etkenler olduğunu ifade etmişlerdir. Sınavlar da algılanan stresi ve TMR skorlarını artıran bir dış etken olarak tanımlanabilir.

TMR tespitinde yalnızca anket taraması yapılarak ancak çok kısıtlı sonuçlar elde edilebilir. TMR şüphesi olan bireyler ileri klinik ve radyolojik muayene ile araştırılmalıdır. Diğer yandan bu çalışma yalnızca, diş hekimliği fakültesi öğrenci popülasyonunda ilerletilmiştir. Dâhil edilen katılımcıların cinsiyet dağılımları homojen değildir. Bu durum çalışmanın sonuçlarına etki etmiş olabilir. Bu sebeple, gelecekteki çalışmalar; daha büyük sayıda homojen katılımlı bir popülasyon üzerinde ve klinik ve radyolojik muayene ile birlikte TMR araştırması yapmalıdır.

\section{SONUÇ}

Bu çalışmanın bulguları ile aşağıdaki sonuçlara ulaşılmıştır;

- Sinav TMR skorlarını artırmaktadır.

- Bruksizm ve algılanan stres arasında güçlü bir ilişki vardır.

- Kadınlar erkeklerden daha yüksek oranda algılanan stres skorları ve TMR skorları göstermiștir.

- Aile yanında veya ayrı yaşamak algılanan stres skoru ve TMR skorları arasında herhangi bir ilişki kurulamamıștır.

\section{Teșekkür}

Çalışmanın verilerinin toplanmasında büyük katkı sağlayan Stj. Dt. Beyza Solmaz'a teșekkür ederiz.

\section{KAYNAKLAR}

1. Okeson JP. Management of Temporomandibular Disorders and Occlusion. 2019. 8: p 146-50

2. Kordass B, Hugger A, Bernhardt O. Correlation between computer-assisted measurements of mandibular opening and closing movements and clinical symptoms of temporomandibular dysfunction. Int J Comput Dent. 2012;15:93-107

3. Suma S, Veerendra Kumar B. Temporomandibular disorders and functional somatic syndromes: deliberations for the dentist. Indian J Dent Res. 2012;23:52936

4. Shetty S, Pitti V, Satish Babu CL, Surendra Kumar GP, Deepthi BC. Bruxism: a literature review. J Indian Prosthodont Soc. 2010;10:141-48. 
5. Wieckiewicz M, Paradowska-Stolarz A, Wieckiewicz W. Psychosocial aspects of bruxism: the most paramount factor influencing teeth grinding. Biomed Res Int. 2014;2014:469187

6. Bader, G. and G.J.S.m.r. Lavigne, Sleep bruxism; an overview of an oromandibular sleep movement disorder. 2000. 4: p. 27-43

7. Manfredini, D. and F.J.J.O.p. Lobbezoo, Role of psychosocial factors in the etiology of bruxism. 2009. 23: p. 153-66

8. Lobbezoo, F., Jacobs, R., De Laat, A., Aarab, G., Wetselaar, P., Manfredini, D. Chewing on bruxism. Diagnosis, imaging, epidemiology and aetiology. Ned. tijdschrift voor tandheelkunde, 2017 124:309-16.

9. Abe Y, Suganuma T, Ishii M, Yamamoto G, Gunji T, Clark GT, et al. Association of genetic, psychological and behavioral factors with sleep bruxism in a Japanese population. J Sleep Res. 2012 Jun;21:289-96.

10. Hublin C, Kaprio J, Partinen M, Koskenvuo M. Sleep bruxism based on self-report in a nationwide twin cohort. J Sleep Res. 1998 Mar; 7:61-7

11. Goldstein BH. Temporomandibular disorders: a review of current understanding. Oral Surg Oral Med Oral Pathol Oral Radiol Endod. 1999;88:379-85.

12. Manfredini D, Lobbezoo F. Relationship between bruxism and temporomandibular disorders: a systematic review of literatüre from 1998 to 2008. Oral Surg Oral Med Oral Pathol Oral Radiol Endod. 2010;109:26-50.

13. de Oliveira AS, Dias EM, Contato RG, Berzin F. Prevalence study of signs and symptoms of temporomandibular disorder in Brazilian college students. Braz Oral Res 2006;20:3-7.

14. Bevilaqua-Grossi D, Chaves TC, de Oliveira AS, Monteiro-Pedro V. Anamnestic index severity and signs and symptoms of TMD. Cranio 2006;24:112-8.

15. Marshall LL, Allison A, Nykamp D, Lankea S. Perceived stress and quality of life among doctor of pharmacy students. Am J Pharm Educ. 2008;72:137-45

16. Saczuk K, Lapinska B, Wilmont P, Pawlak L, Lukomska-Szymanska M. Relationship between Sleep Bruxism, Perceived Stress, and Coping Strategies. Int. J. Environ. Res. Public Health. 2019; 16:3193.

17. Beck DL, Hackett MB, Srivastava R, McKim E, Rockwell B. Perceived level and sources of stress in university professional schools. J Nurs Educ. 1997;36:180-6

18. Hinton JW, Rotheiler E. Stress, health and performance in university students. Z Gesamte Hyg. 1990;36(12):634-5
19. Reifman A, Dunkel-Schetter C. Stress, structural social support, and wellbeing in university students. J Am Coll Health. 1990;38:271-7

20. Ross SE, Niebling BC, Heckert TM. Sources of stress among college students. Social Psychology. 1999;61:841-6

21. Kaynak, BA, Taş, S, Salkın, Y. The accuracy and reliability of the Turkish version of the Fonseca anamnestic index in temporomandibular disorders. Cranio $₫$, 2020, 1-6.

22. Erci, B. Reliability and validity of the Turkish version of perceived stress scale. Anadolu Hemşirelik ve Sağllk Bil Derg, 2006, 9.1: 58-63.

23. Quadri MF, Mahnashi A, Al Almutahhir A, Tubayqi $\mathrm{H}$, Hakami A, Arishi M Alamir A. Association of awake bruxism with khat, coffee, tobacco, and stress among jazan university students. Int J Dent. 2015;30:2015.

24. Ahlberg J, Rantala M, Savolainen A, Suvinen T, Nissinen M, Sarna S, et al. Reported bruxism and stress experience. Commun Dent Oral Epidemiol.2002;30:405-8.

25. Akhter R, Morita M, Esaki M, Nakamura K, Kanehira T. Development of temporomandibular disorder symptoms: a 3-year cohort study of university students. J Oral Rehabil. 2011;38(6):395-403.

26. Cavallo, P; Carpinelli, L; Savarese, G. Perceived stress and bruxism in university students. BMC research notes, 2016, 9.1: 1-6.

27. Westrup DA, Keller SR, Nellis TA, Hicks RA. Arousability and bruxism in male and female college students. Percept Mot Skills. 1992;75:796-8.

28. Hicks RA, Conti PA, Bragg HR. Increases in nocturnal bruxism among college students implicate stress. Med Hypotheses. 1990;33:239-40.

29. Shah M, Hasan S, Malik S, Sreeramareddy C. Perceived stress, sources and severity of stress among medical undergraduates in Pakistani medical school. BMC Med Educ. 2010;10:2.

30. Warren MP, Fried JL. Temporomandibular disorders and hormones in women. Cells Tissues Organs 2001;169:187-92.

31. Wang J, Chao Y, Wan Q, Zhu Z. The possible role of estrogen in the incidence of temporomandibular disorders. Med Hypotheses 2008;71:564-7.

32. Türken, R; Büyük, SK; Yasin, YA. Diş Hekimliği Fakültesi Öğrencilerinde Temporomandibular Eklem Rahatsızlıklarının ve Ağız Sağlığı Alışkanlıklarının Değerlendirilmesi. Acıbadem Univ. Sağlık Bilim. Derg, 2020, 2: 208-13. 